\title{
催化不对称硼化反应构建轴手性芳基硼化合物
}

\author{
张 健 谭 斌* \\ (南方科技大学化学系 深圳格拉布斯研究院 广东深圳 518055)
}

\section{Catalytic Asymmetric Borylation to Construct Axially Chiral Arylborons}

\author{
Zhang, Jian Tan, Bin* \\ (Shenzhen Grubbs Institute and Department of Chemistry, Southern University of Science and Technology, \\ Shenzhen, Guangdong 518055)
}

轴手性联芳基骨架是一类重要的结构单元, 广泛存 在或应用于天然产物、手性材料、手性配体和手性催化 剂当中. 正因如此, 对映选择性构建轴手性联芳基骨架 引起了有机合成化学家的广泛关注, 催化不对称构建轴 手性联芳基化合物近年来获得了突飞猛进的发展 ${ }^{[1-3]}$. 手性有机嗍化合物是有效构建光学活性分子的重要中 间体 ${ }^{[4]}$, 其中含中心手性的有机嗍化合物的构建已有文 献报道, 而含碳一嗍轴手性的有机嗍化合物却无报道. 发展碳-硼轴手性化合物的催化不对称合成方法具有较 大的挑战性. 相比联芳基化合物中的 $\mathrm{C}\left(\mathrm{sp}^{2}\right)-\mathrm{C}\left(\mathrm{sp}^{2}\right)$ 键 $(0.149 \mathrm{~nm}), \mathrm{C}\left(\mathrm{sp}^{2}\right)$ - $\mathrm{B}$ 键 $(0.158 \mathrm{~nm})$ 更长 (Scheme 1a), 这 就使得碳-硼键的旋转能垒相对较低, 因而更难以控制 轴手性 ${ }^{[5]}$.

Miyaura 硼化反应 ${ }^{[6]}$ 是指芳基卤化物和联硼酸频哪 醇酯 $\left(\mathrm{B}_{2} \mathrm{pin}_{2}\right)$ 之间的偶联反应，它是一种构建芳基硼化 物的有效手段. 近日, 宋秋玲课题组 ${ }^{[7]}$ 利用钯催化的不 对称 Miyaura 硼化反应, 高效地构建了一类轴手性芳基 嗍化合物(Scheme 1b), 首次实现了含有碳- 嗍键轴手性 化合物的催化不对称合成.

该催化不对称反应的最优条件是以 $\mathrm{Pd}(\mathrm{OAc})_{2}$ (4 $\mathrm{mol} \%)$ 和手性膦配体 (6 mol\%)为催化剂、 $\mathrm{K}_{3} \mathrm{PO}_{4}$ 为碱、 $1,4-$ 二氧六环为溶剂, 反应温度为 $30{ }^{\circ} \mathrm{C}$. 作者在最优条 件下进行了底物适用性的考察(Scheme 2). 结果显示, 该反应具有较高的官能团兼容性, 不同类型取代的荎 基溴代物均可顺利进行，如化合物 $3 \mathbf{a} \sim \mathbf{3 c}$. 不仅如此, 氮杂环芳基溴代物(3d)和多取代的芳基溴代物(3e)也可 兼容. 此外, 对于各类非对称联嗍试剂 $(\mathbf{3} \mathbf{3} \sim \mathbf{3 h})$, 反应均 能以较高的对映选择性得到相应的轴手性芳基硼化合 物. (a) Bond length of stereogenic axis in atropisomers

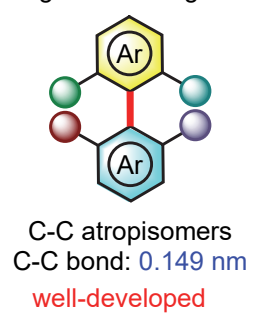

(b) Miyaura borylation for the synthesis of C-B atropisomers
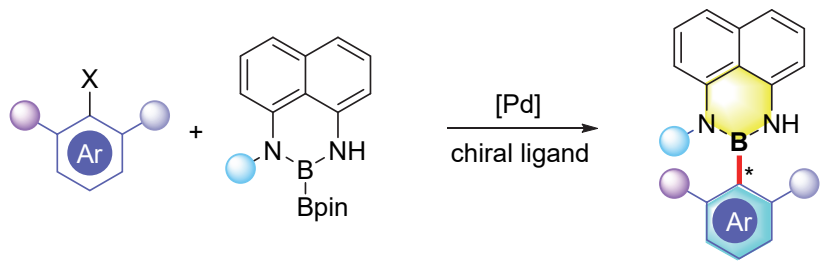

图式 1 不对称 Miyaura 嗍化反应构建轴手性芳基嗍化合物 Scheme 1 Asymmetric borylation to construct axially chiral arylborons

该催化不对称反应在 $1.0 \mathrm{mmol}$ 规格下也可以顺利 进行, 收率和对映选择性均可保持. 另外, 作者对轴手 性芳基嗍化合物的应用进行了初步探索. 如 Scheme 2 所示，化合物 3a 在正丁基锂的作用下转化成氨基锂，该 中间体可与各类亲电试剂反应, 进而得到一系列衍生化 的轴手性芳基嗍化合物 $(\mathbf{4 a} \sim \mathbf{4 c})$, 其中包括具有潜在应 用价值的轴手性膦配体 (4c). 此外，作者对这类化合物 的稳定性进行了研究. 实验发现, 化合物 3a 具有较高的 消旋能垒 $(\Delta G=116.1 \mathrm{~kJ} / \mathrm{mol})$, 该结果验证了这类碳-硼 轴手性骨架的稳定性.

该反应可能的机理如 Scheme 3 所示: 首先芳基溴 代物 I 与光活性 $\operatorname{Pd}(0)$ 进行氧化加成, 生成手性芳基钯中

* Corresponding author. E-mail: tanb@sustech.edu.cn. Published online August 25, 2021. 

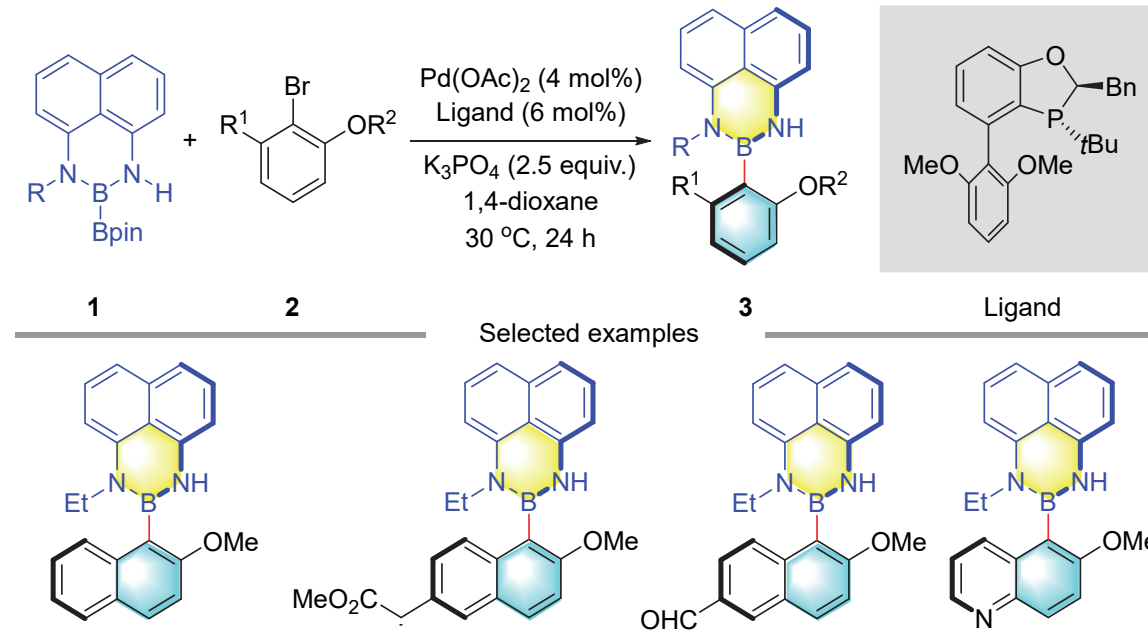

2

3

Ligand

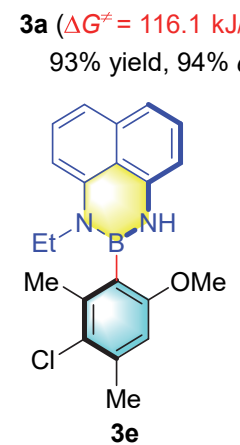

M
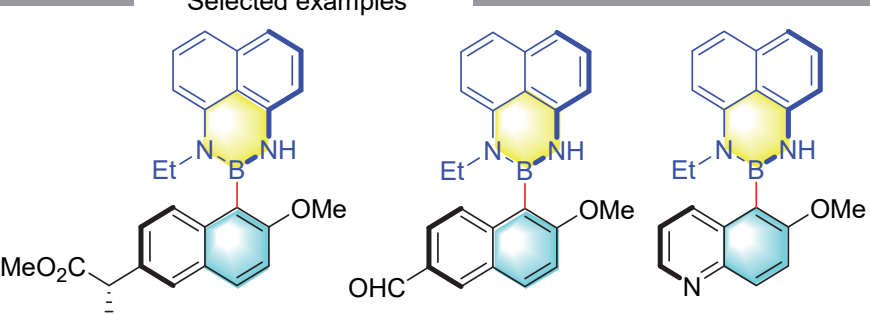

Me $3 b$

$3 c$

$3 d$

$74 \%$ yield, $94 \%$ de

$96 \%$ yield, $92 \%$ ee

$92 \%$ yield, $88 \%$ ee
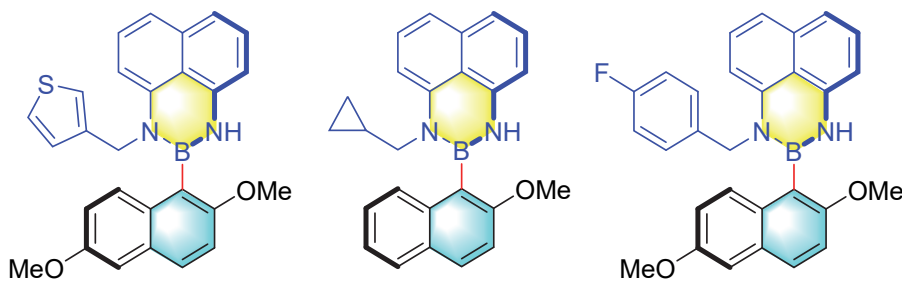

$3 \mathrm{~g}$

3h

$60 \%$ yield, $98 \%$ ee

$3 f$

$73 \%$ yield, $92 \%$ ee

$86 \%$ yield, $91 \%$ ee $99 \%$ yield, $92 \%$ ee

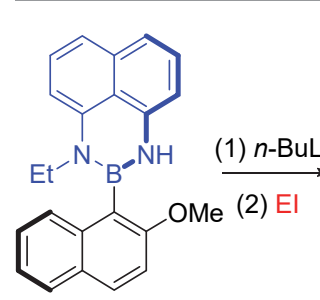

$3 a$

$94 \%$ ee

Selected transformations

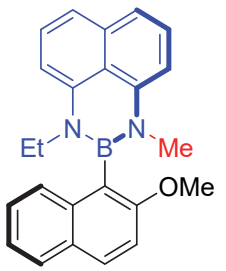

$4 a$

96\% yield, $95 \%$ ee

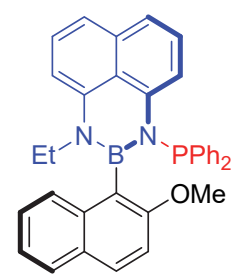

4b

$42 \%$ yield, $99 \%$ ee (recrystallization)

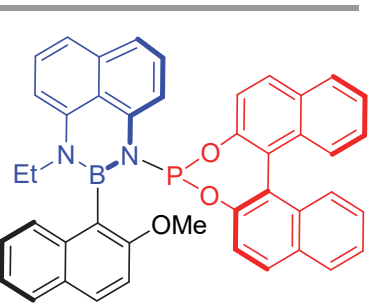

4c

$25 \%$ yield, $>20: 1 d r$

图式 2 底物拓展与转化

Scheme 2 Substrate scope and transformations

间体 II. 随后该中间体发生阴离子交换，生成中间体 III. 中间体 III 与非对称二硼试剂之间进行转金属化, 生成中间体 IV. 中间体 IV 发生还原消除即可生成轴手 性芳基硼化合物 $\mathbf{V}$, 而手性 $\operatorname{Pd}(0)$ 催化剂则再生, 完成循 环.

总而言之, 作者利用钯催化芳基溴代物与非对称联 嗍试剂的不对称硼化反应, 实现了含碳一嗍键的轴手性 芳基嗍化合物的高效构建. 该反应具有底物范围广、产 率和对映选择性高等优点, 为轴手性芳基硼骨架的催化 不对称构建提供了新策略, 而该类结构新颖的产物也丰 富了阻旋异构体的类型. 这些新型的轴手性芳基硼化合 物有望在不对称催化等领域发挥重要作用.
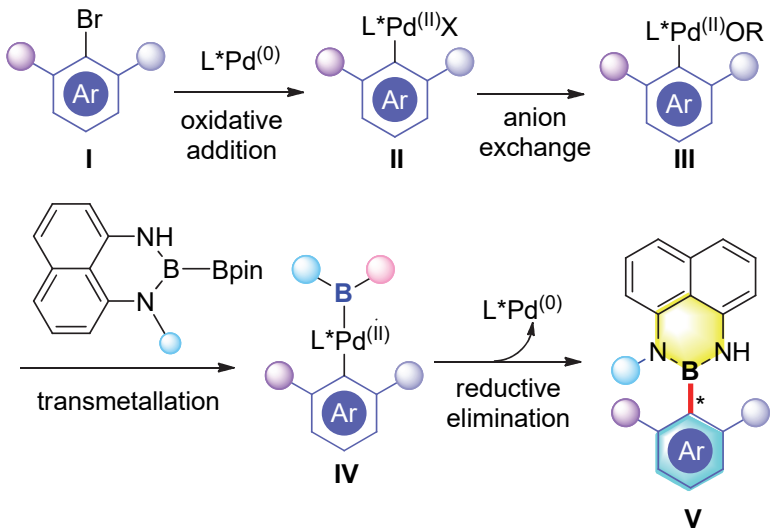

图式 3 可能的反应机理

Scheme 3 Possible reaction mechanism 


\section{References}

[1] Cheng, J. K.; Xiang, S.-H.; Li, S.; Ye, L.; Tan, B. Chem. Rev. 2021, $121,4805$.

[2] Wang, Y.-B.; Tan, B. Acc. Chem. Res. 2018, 51, 534.

[3] Wencel-Delord, J.; Panossian, A.; Leroux, F. R.; Colobert, F. Chem. Soc. Rev. 2015, 44, 3418.
4] Fyfe, J. W. B.; Watson, A. J. B. Chem 2017, 3, 31

[5] Mazzanti, A.; Mercanti, E.; Mancinelli, M. Org. Lett. 2016, 18, 2692.

[6] Ishiyama, T.; Murata, M.; Miyaura, N. J. Org. Chem. 1995, 60, 7508.

[7] Yang, K.; Mao, Y.; Xu, J.; Wang, H.; He, Y.; Li, W.; Song, Q. J. Am. Chem. Soc. 2021, 143, 10048.

(Cheng, F.) 